\title{
Effect of Extracted Compositions of Liquefaction Residue on the Structure and Properties of the Formed-coke
}

\author{
SONG Yong-hui ${ }^{\mathrm{a}}$, MA Qiao-na ${ }^{\mathrm{b}, *}$ and HE Wen-jin ${ }^{\mathrm{c}}$ \\ Metallurgical Engineering Technology Research Centre of Shaanxi Province \\ Xi'an University of Architecture \& Technology, Shaanxi Xi'an-710055, P.R. China \\ asyh1231@126.com \\ bmaqn0724@126.com \\ c233400766@qq.com
}

\begin{abstract}
The purpose of this paper is to study the effect of extracted compositions of the de-ash liquefaction residue (D-DCLR) on pyrolysis products yields, compressive strength and composition of the formed-coke, which was prepared by co-pyrolysis of the low metamorphic pulverized coal and D-DCLR. The scanning electron microscope (SEM) and the Fourier Transform Infrared (FT-IR) were used to characterize the morphology and functional group of the formed-coke, respectively. The results showed that the extracted compositions of D-DCLR were heavy oil (HS), asphaltene (A), pre-asphaltene (PA) and tetrahydrofuran isolusion (THFIS), whose contents were $5.10 \%, 40.90 \%, 14.4 \%, 39.60 \%$, respectively. During the pyrolysis process, HS was the main source of tar, and HS, A as well as PA were conducive to improve gas yields. The THFIS helped to improve the yield of the formed-coke up to $89.5 \%$, corresponding to the compressive strength was only $147.7 \mathrm{~N} / \mathrm{ball}$ for the coke. A and PA were the key factors affecting the compressive strength and surface structure of the formed-coke. The compressive strength of coke could be up to $728.0 \mathrm{~N} /$ ball with adding D-DCLR, which reduced by $50 \%$ after the removal of A and PA. The FT-IR analysis showed that the types of surface functional groups of the formed-coke were remained the same after co-pyrolysis, but the absorption peak intensity of each functional group was changed.
\end{abstract}

\section{Introduction}

Coal resources reserves are abundant in China, where stored full range of coal species but its distribution is very uneven. Low metamorphic bituminous coal (long-flame coal, non-caking coal, weakly caking coal) accounted for $51.23 \%$, and mainly distributed in Shanxi, Shaanxi and Inner Mongolia, Ningxia and other regions. Low rank coal

\footnotetext{
*Corresponding author: maqn0724@126.com
} 
characterized by low rank and ignition, high volatile and tar yield in Ordos Basin and Northern Shaanxi, is a kind of high-quality steam coal, and is widely used in power plants and exports, currently. In addition, through the medium or low temperature distillation process to produce semi coke, tar and gas are new ways explored in recent years. At present, semi coke has achieved a partial substitute for coke, and it has been widely used in the ferroalloy, calcium carbide and gasification industry. Furthermore, it also contributes to achieving energy conservation and tapping potential synergies for enterprise. The raw materials for blue carbon are lump coal, which were ground within $20 \mathrm{~mm}$ to $80 \mathrm{~mm}$, but the yields of it was only $30 \%$ to $40 \%$ during the actual coal production. The pulverized coal production was large, and there was no effective way to use. So the study on pyrolysis of pulverized coal with low metamorphic has become a key problem. The pulverized coal outputted at almost 100 million tons per year or more, and according to the average content of oil rate $8 \%$ which can increase almost 8 million tons of refined oil a year if all of it recovered before combustion or gasification. In recent years, pyrolysis of low metamorphic pulverized coal mostly concentrates on studying solid heat carrier, which still doesn't achieve commercial applications by far. This is because that the heavy tar and semi coke fine particles will be adhered to the inner wall of the cyclone and the cooling circuit, which will have an impact on the stable operation of the system. Nevertheless, the rapid mixing and heating of pulverized coal with solid heat carrier is also the main reason, so is the rapid separation of volatiles.

Direct coal liquefaction residue (DCLR) generally contains about $30 \%$ of the heavy oil (HS) and almost $25 \%$ of asphaltene (A) and pre-asphaltene (PA), so through pyrolysis to produce oil has become an economical and reasonable way. CHU Xi-Jie, et al ${ }^{[1]}$ studied the kinetics of pyrolysis of residue by using the distributed activation energy model (DAEM), and found the activation energy of this pyrolysis was about $170 \mathrm{~kJ} / \mathrm{mol}$. Ouchi, et a ${ }^{[2]}$ used the coal hydrocracking products, A and PA, for re-hydrocracking, and explored the reaction mechanism of this reaction by detecting changes in the chemical structure of the liquefied product. The oil came from ShengLi oil field was used as extraction agent by ZHONG Jin-long $^{[3]}$ to separate the organic soluble matter from DCLR, which showed that the extraction rate and the oil content can achieve to $50 \%$ and $58 \%$ when the extraction temperature was $130^{\circ} \mathrm{C}-150^{\circ} \mathrm{C}$, residence time was $15-30 \mathrm{~min}$, and mass ratio of solvent and residue was 4:1-5:1. TG analysis of DCLR and its solvent extracts carried out by LIU Peng-fei ${ }^{[4]}$ showed that the weight loss rates of HS, A, PA, THFIS at $800^{\circ} \mathrm{C}$ were about $88 \%, 67 \%, 49 \%$ and $19 \%$, respectively. Among them, the weight loss of HS, A and PA started at about $200^{\circ} \mathrm{C}, 200^{\circ} \mathrm{C}, 150{ }^{\circ} \mathrm{C}$ and finished at about $475^{\circ} \mathrm{C}, 540{ }^{\circ} \mathrm{C}, 400^{\circ} \mathrm{C}$, respectively. THFIS began to have a significant weight loss in the high temperature of $450^{\circ} \mathrm{C}$, during which was always slower. Motoyuki ${ }^{[5]}$ suggested in his study that synergistic effect of co-pyrolysis for DCLR with the tire could greatly improve the conversion rate and yields of oil and asphaltene.LI Jun's ${ }^{[6,7]}$ studies had shown that some low-temperature volatile components obtained in heavy oil and asphaltene cannot volatilize at low temperature, while disintegrated at higher temperature.

The low metamorphic pulverized coal has poor adhesiveness, so that it is difficult to form high-quality coke during the pyrolysis process. At the same time, the studies of liquefaction residues are mainly concentrated in the pyrolysis, gasification, pyrolysis characteristics, product composition and other aspects; the study of the co-pyrolysis of low rank coal and liquefaction residues to prepare the formed-coke is rarely reported. In view of this, the authors developed a process that using co-pyrolysis technology to maximize the recovery of the tar during the preparation of the formed-coke (patent: ZL201210400639.X) with low metamorphic pulverized coal as raw materials and D-DCLR as additive. The results showed that this technology is an effective way to utilize the low metamorphic 
pulverized coal and D-DCLR. Previous studies ${ }^{[8]}$ have shown that a kind of high-quality formed-coke with dense and uniform surface can be obtained by co-pyrolysis of long-flame coal and D-DCLR, which intensity can be $728 \mathrm{~N} /$ ball at $800^{\circ} \mathrm{C}$. The yields of pyrolysis tar and gas increased, and the compressive strength of coke first increased but decreased later with the increasing adding proportion of D-DCLR. The content of gelatinous body, large amount of volatile and the increased ash component are the main factors affecting the compressive strength of the formed-coke among the pyrolysis process. The formed-coke can be used as industrial, civilian lump fuel or gasification materials; and replacing the regular coke, applied in calcium carbide, ferroalloy production or blast furnace and other industries; meanwhile, tar can change into fuel oil by further hydro-treating process.

The feasibility of co-pyrolysis technology with low rank pulverized coal and D-DCLR to prepare high-quality formed-coke has been confirmed. In this study, the D-DCLR was constantly extracted three times, by using the Soxhlet extraction with the hexane, toluene, and tetrahydrofuran as extracting agent, respectively; then studied the influence of the extracted composition of the D-DCLR on structure and compressive strength of the formed-coke.

\section{Experimental Procedure}

\subsection{Materials}

The low-metamorphic fork pulverized coal is a kind of long flame coal from Shenmu Sunjiacha (SJC), the D-DCLR is from a coal chemical industry that in the west of China. Proximate and ultimate analyses of the samples are shown in Table 1. Extractants used in the experiments are toluene, hexane and tetrahydrofuran, and all of which are analytical reagents.

Table 1 Proximate And Ultimate Analysis Of Sjc And D-Dclr (Wt/\%)

\begin{tabular}{|c|c|c|c|c|c|c|c|c|c|}
\hline \multirow{2}{*}{ Sample } & \multicolumn{4}{|c|}{ Proximate analysis } & \multicolumn{5}{|c|}{ Ultimate analysis } \\
\hline & $\mathrm{Mt}$ & Aad & Vad & FCad & $\mathrm{Cad}$ & Oad & $\mathrm{Had}$ & $\mathrm{Nad}$ & St,ad \\
\hline SJC & 3.41 & 2.64 & 37.79 & 56.16 & 76.4 & 17.6 & 4.7 & 1.0 & 0.3 \\
\hline D-DCLR & 0.26 & 10.62 & 33.19 & 55.93 & 78.58 & 14.83 & 4.44 & 0.81 & 1.34 \\
\hline
\end{tabular}

Proximate analysis shows that, SJC and D-DCLR belong to high volatile matter and the ash content is of the large difference between the two. The ash content of the pulverized SJC is only $2.64 \%$, while the D-DCLR is $10.62 \%$. Ultimate analysis indicates that both D-DCLR and SJC contain high oxygen content, the sulfur content of D-DCLR is $1.34 \%$, which is higher than SJC. 


\subsection{Extraction}

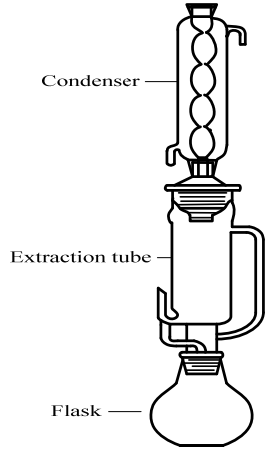

Fig.1 Soxhlet extraction experimental device

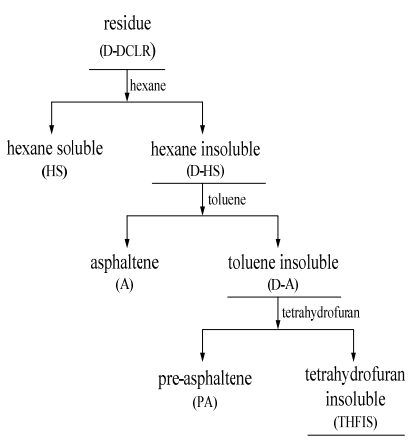

Fig.2 Soxhlet extraction diagram of D-DCLR

Soxhlet extraction experimental device has been shown in Fig.1, and the extraction process shows in Fig.2. This extraction experiments refer to the method of the national standard GB/T2292-1977, and the four components of liquefaction are separated and determinated by using the hexane, toluene, and tetrahydrofuran, respectively ${ }^{[9]}$.

The sieved D-DCLR were weighed $30 \mathrm{~g}$ accurately (60 mesh accounted for more than $95 \%$ ), and placed in a drying oven at $100^{\circ} \mathrm{C}$ for $24 \mathrm{~h}$. First, the D-DCLR was extracted by hexane at the ratio of 1: 5 with the temperature of $80^{\circ} \mathrm{C}$ for $48 \mathrm{~h}$. After that, the hexane insoluble (D-HS) was dried at $100^{\circ} \mathrm{C}$ for $24 \mathrm{~h}$ and weighted $6 \mathrm{~g}$ to prepare the formed-coke, the rest of which was extracted by toluene at the same condition for $48 \mathrm{~h}$. Then, the toluene insoluble was dried and weighted $6 \mathrm{~g}$ to prepare the coke, the rest of which was extracted by tetrahydrofuran at the ratio of $1: 7$ with the temperature of $120^{\circ} \mathrm{C}$ for $48 \mathrm{~h}$, after that the insoluble was dried and weighted $6 \mathrm{~g}$ to prepare the formed-coke.

\subsection{Preparation}

SJC、D-DCLR、D-HS、D-A and THFIS were ground and sieved into the form of powder (less than $250 \mu \mathrm{m}$ ). Then the samples were oven-dried at $100^{\circ} \mathrm{C}$ for $24 \mathrm{~h}$. The D-DCLR (D-HS, D-A, D-PA) mixed with SJC at the mass ratio of 2:3, and then weighed $15 \mathrm{~g}$ accurately. After adding about $10 \%$ water, the samples were mixed and then placed on the make-up machine (FYD-40-A) with the pressure of $6 \mathrm{MPa}$ to form the briquette of $\Phi 30 \mathrm{~mm} \times 25 \mathrm{~mm}$. After putted it under the air for $24 \mathrm{~h}$, the formed samples were putted into a quartz reactor. And then the temperature was increased to $800^{\circ} \mathrm{C}$ with a heating rate of $5^{\circ} \mathrm{C}$ $/ \mathrm{min}$ and held for $90 \mathrm{~min}$ to obtain the formed-coke.

\subsection{Analysis}

The coke was placed on make-up machine (FYD-40-A). As its minor axis perpendicular to loading platform, increased the pressure at a constant rate until the coke was crushed. At this time, the data on the dashboard was suddenly decreased and recorded it as $\mathrm{P}(\mathrm{Pa})$. The compressive strength of coke can be calculated by Eq. (1) 


$$
\mathrm{F}=\mathrm{P} \cdot\left(\frac{1}{4} \pi \mathrm{D}^{2}\right)
$$

where $\mathrm{D}$ and $\mathrm{F}$ are the diameter and the compressive strength of coke respectively, $\mathrm{m}$ and $\mathrm{N} / \mathrm{ball}$.

The proximate and ultimate analysis of raw materials and formed coke were carried out according to the methods of GB/T2001-1991 and GB/T214-2007. The morphology of coke was characterized by SEM (JSM-6360LV, Japan).And the structure of coke were analyzed by FT-IR(IR Prestige-21, Japan), which resolution was $4 \mathrm{~cm}^{-1}$ and collecting IR information at a wavelength of $400 \mathrm{~cm}^{-1}-4000 \mathrm{~cm}^{-1}$.

\section{Results and Discussion}

\subsection{Soxhlet extraction}

The solvent extract yields of D-DCLR by Soxhlet extraction are shown in Table 2, which shows that A and THFIS are the main components of D-DCLR and the amounts are about $40.9 \%$ and $39.6 \%$, while the HS is only $5.10 \%$.

The reaction mechanism of coal liquefaction shows that $\mathrm{A}$ and PA were the intermediate products of coal liquefaction, which can be further converted to heavy oil ${ }^{[10]}$. It reported in the literature [11] that the content of HS, A, PA and THFIS of liquefaction residue was about $30 \%, 23 \% 10 \%$ and $38 \%$ respectively, which was quite different from the results of this experiment. This may be caused by differences in the liquefaction process, and the residue used in this experiment was de-oiled.

Table 2 Solvent Extract Yields Of D-Dclr (Wt/\%)

\begin{tabular}{ccccc}
\hline Sample & HS & A & PA & THFIS \\
\hline 1 & 5.10 & 40.80 & 15.20 & 38.90 \\
2 & 5.07 & 41.04 & 13.60 & 35.65 \\
Average & 5.10 & 40.90 & 14.40 & 39.60 \\
\hline
\end{tabular}

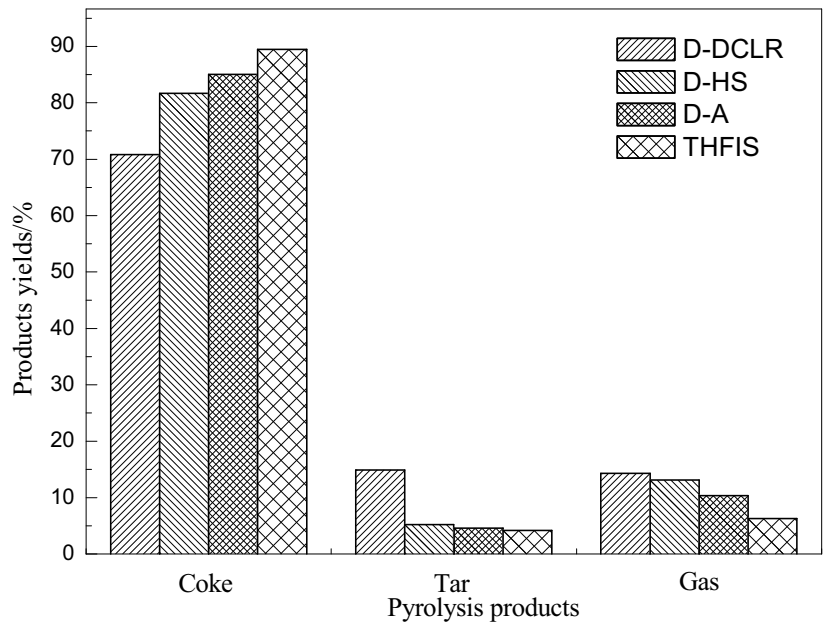

Fig.3 The analysis of pyrolysis products 
The formed-coke was prepared by the steps above and the results of co-pyrolysis products yields were shown in Fig.3. It shows that the coke yield increases, while the yields of tar and coal gas reduce with the order of D-DCLR, D-HS, D-A, THFIS mixed with SJC to prepare the formed-coke, respectively. The ash of DCLR is mainly present in the THFIS, whose weight loss was $10 \%$ at $800^{\circ} \mathrm{C}^{[4]}$. The increase of coke yield is attributed to the fact that the weight loss of THFIS is not obvious in high temperature. During the co-pyrolysis process, HS was transformed into oils, A and PA could be cleaved to produce oil and gas, so the yields of tar and gas were decreased. The yields of coke and tar changed obviously after the removal of HS with the coke increased by $10.89 \%$, the tar decreased by $9.69 \%$ and the gas showed a little change of $1.2 \%$, which indicated that HS was the main factor affecting the yield of tar. This is due to the fact that the weight loss of HS is about $92 \%$ at $500^{\circ} \mathrm{C}$, and there is no cleavage and aggregation during this co-pyrolysis process, while it separated out in the form of oil $/ \operatorname{tar}^{[7]}$. In addition, the hydrogenation of heavy oil can further generate tar or some other light oil components due to the high hydrogen content in SJC. The yield of gas reduced by $2.73 \%$ and $4.08 \%$ after the removal of A and PA, while their tar yields were decreased by $0.63 \%$ and $0.37 \%$. It is caused by the different thermal stabilities of A and PA. Among the co-pyrolysis process, both A and PA can crack into gas, but the A not only can be cracked but also evaporated; so that it is easier for A to make polymerization reaction and form oil and gas than $\mathrm{PA}^{[12]}$.

\subsection{Compressive strength}

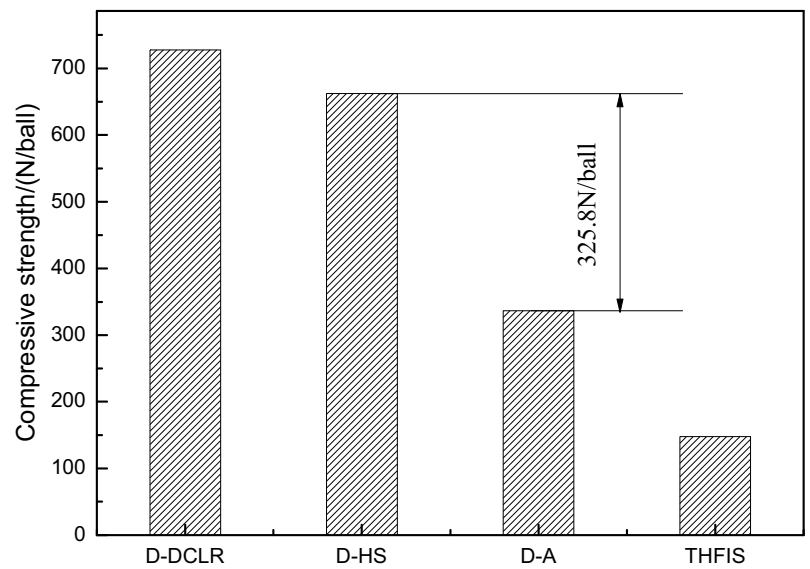

Fig.4 Analysis of compressive strength of formed Coke

The results of compressive strength of the formed-coke have been shown in Fig.4. It shows that the compressive strength of the formed-coke decreased gradually in this analysis. And the compressive strength of coke can up to $728 \mathrm{~N} /$ ball when using D-DCLR as additive, while it can reduce to $147.7 \mathrm{~N} / \mathrm{ball}$ when using THFIS. After the removal of HS, A, and PA, the compressive strength reduced by $65.3 \mathrm{~N} /$ ball, $325 \mathrm{~N} / \mathrm{ball}$ and $189.2 \mathrm{~N} / \mathrm{ball}$, respectively. Among them, the compressive strength decreased obviously after the removal of A, which was almost the half of the maximum. It indicates that $\mathrm{A}$ and PA are the main factors affecting the compressive strength of the formed-coke, and A plays a more significant role than PA. It is due to the fact that A and PA can form gelatinous layer which has strong plasticity properties and good flowing ability. This gelatinous body can distribute between the pulverized coals and bond them together to form high quality formed-coke. In contrast, THFIS mainly compose of unreacted coal, catalyst or minerals, and all of them cannot form 
gelatinous body during the co-pyrolysis process; so that they cannot effectively bond the pulverized coal together, and the compressive strength of the formed-coke is very poor. HS has little influence on compressive strength of the coke which is caused by the fact that most of the HS is precipitated in the form of tar.

\subsection{SEM analysis}

The SEM images of the formed coke were showed in Fig.5, where A, B, C, D corresponded to using D-DCLR, D-HS, D-A and THFIS as additive during the co-pyrolysis with STC, respectively. It could be found from Fig.5 (A) to Fig.5 (D) that pore structure of the surface of the formed-coke was more and more obvious, and the particles were arranged from order to disorder. Meanwhile, Fig.5 (C) and Fig.5 (D) appeared cracks. These changes represent that the structure of the coke was becoming looser, which causing the compressive strength decreased. The particles were tightly arranged on the surface of the formed-coke when using D-DCLR as additive, and then the particles were changed to be irregularly arranged when using D-HS. With adding D-A and THFIS, there were appearing large grains and obvious cracks on the surface. Compared with $\mathrm{B}, \mathrm{C}$, and $\mathrm{D}$ that the surface structure of the formed-coke were ready to get looser and appear large pores and cracks. This suggests that A and PA play significant roles in changing the surface structure of the formed-coke, which is consistent with the change of compressive strength. This could also be explained that A and PA can form gelatinous body, which has good flowing property and can widely spread between particles and bond them together to make a uniform and dense pore structure of the formed-coke.
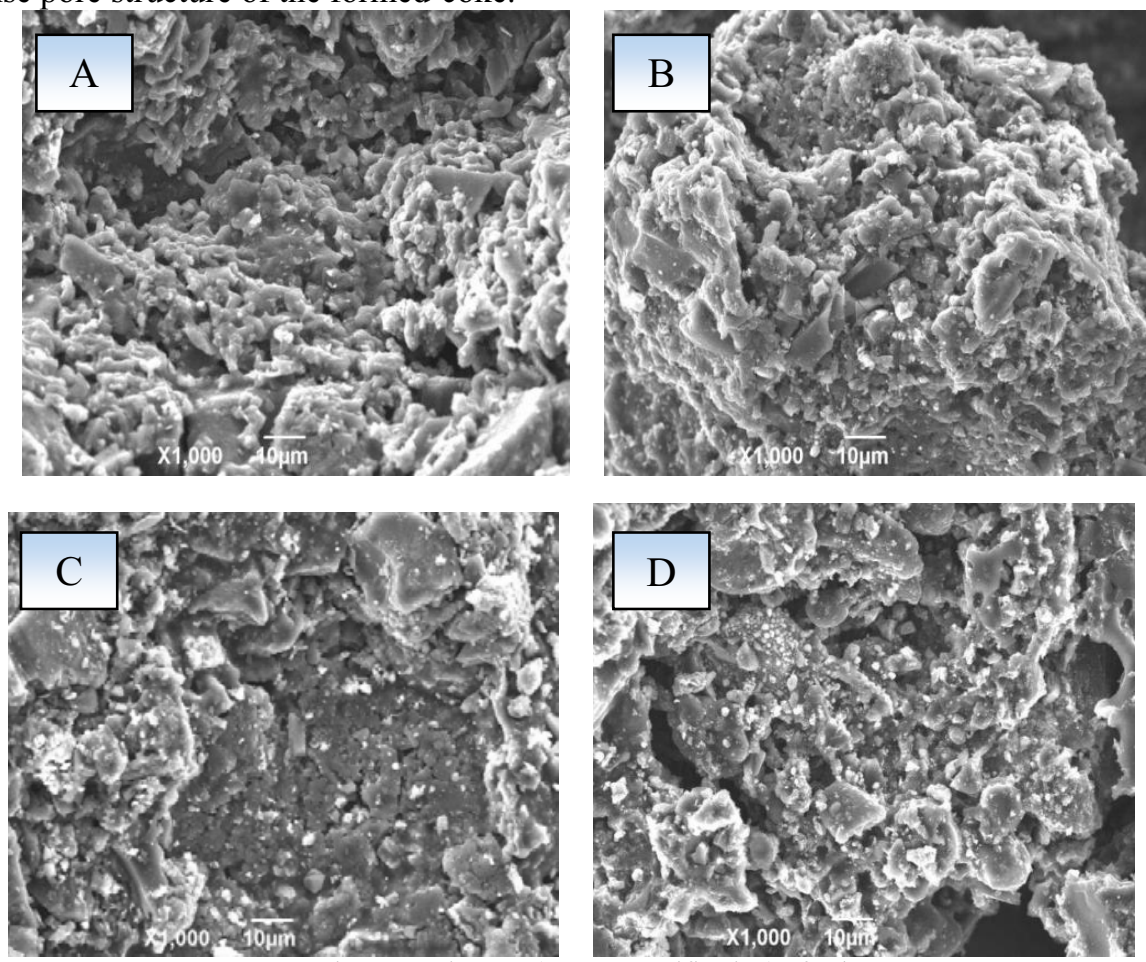

Fig.5 SEM images (1000×magnification) of coke 


\subsection{FT-IR analysis}

Fig.6 showed the IR profiles of the four kinds of formed coke, which were prepared by co-pyrolysis of SJC and the four additives, respectively. As can be seen from Fig.6, types of functional groups of the formed-coke have not changed, and the intensity of absorption peaks is different with the gradual extraction of D-DCLR.

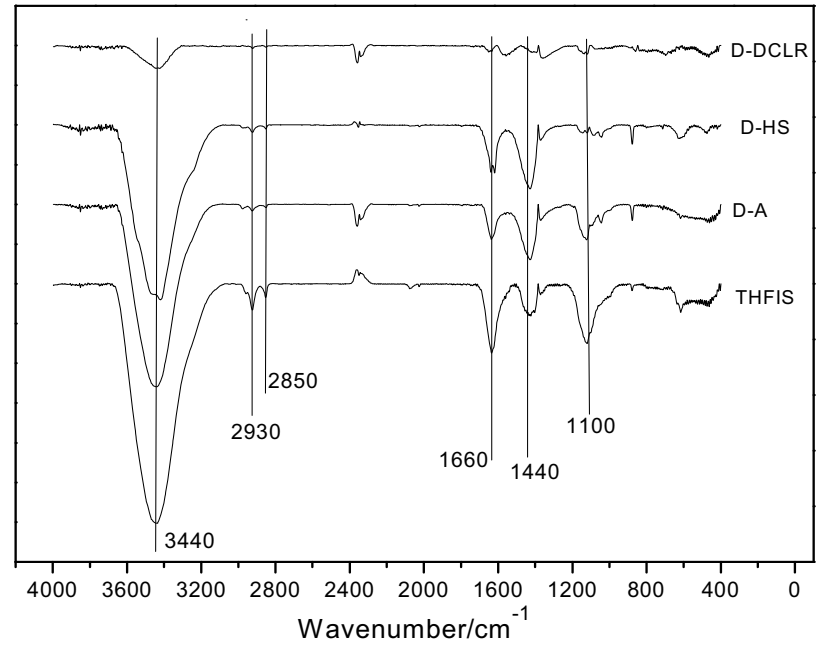

Fig.6 The infrared spectrum of the formed-coke

The intensity of the absorption peak is mainly determined by two factors: one is the extent change of dipole moment in vibrations, as it changes stronger, so does the intensity of the absorption peak; and the other is the electro-negativity of the two atoms at each side of the bond; the absorption become stronger with the increasing retardation of the electro-negativity. The peaks at $3440 \mathrm{~cm}^{-1}$ are for the hydroxyl $(-\mathrm{OH})$ stretching vibration, and these absorption become stronger, which are caused by interactions of the inter-molecular hydrogen bonding. The strengthening interactions of this hydrogen bond is owing to the decreasing substitution reactions of the hydroxyl radicals when HS, A and THFIS respectively make co-pyrolysis with SJC, so that the amount of hydroxyl groups in the structure of the formed-coke are increasing, leading to the effect of inter-molecular hydrogen bonding more significantly.

The weak absorption peaks at $2930 \mathrm{~cm}^{-1}, 2850 \mathrm{~cm}^{-1}$ and $1440 \mathrm{~cm}^{-1}$ are the asymmetrical stretching vibrations, the symmetrical stretching vibrations and the bending vibrations of $-\mathrm{CH}_{2}-$. The intensity of these peaks was enhanced, which might be caused by the strengthened dipole moment vibrations. The peaks intensity at $1440 \mathrm{~cm}^{-1}$ became weaken after the removal of A, which can be explained by the symmetry of molecular structure of the formed-coke.

The peaks at $1660 \mathrm{~cm}^{-1}$ were assigned to the absorption of the stretching vibrations of aromatic carbonyl groups $(-\mathrm{C}=\mathrm{O})$, which become stronger with the stepwise extraction of D-DCLR. It was due to the increasing aromaticity and condensation of the formed-coke, which can make the change of instantaneous dipole moment increased.

The peaks intensity at $1100 \mathrm{~cm}^{-1}$ were gradually increased due to the strengthened asymmetric stretching vibrations, representing the vibrations of ether bonds (-C-O-), which bond energy were high and could be retained during the co-pyrolysis process.

During the co-pyrolysis process, HS, A and PA can form a large number of free radicals fragments, which can randomly combine together to form new structures, so that the 
symmetry of molecular, the interactions of hydrogen bonding, and the electro-negativity between atoms are all changing. Thus, the intensity of absorption peak of each functional group changed significantly.

\section{Conclusions}

A and THFIS are the main composition of D-DCLR by Soxhlet extraction, and the content of them are $40.90 \%$ and $39.60 \%$, while the HS is only $5.10 \%$. The results show that HS is the main factor affecting the yield of tar, and HS, A as well as PA are conducive to improve the yield of gas, and THFIS helps to increase the yield of coke. A and PA are the main factors affecting the compressive strength and surface structure of the formed-coke when using the low metamorphic pulverized coal and D-DCLR to prepare the formed-coke by co-pyrolysis. HS, A and PA can form a large number of free radicals fragments, which can randomly combine together to form new structures during the co-pyrolysis process. As a result, the absorption peaks intensity of each functional group was changed, but their types were remained the same.

\section{Acknowledgment}

The authors appreciate the financial support from the Key Laboratory of Special Shaanxi Province Department of Education (13JS059), Research project of Yulin (2012CXY1-7), the Science and Technology Planning of Shaanxi Province (2011KTDZ01-05-01), the Special Foundation of Xi'an University of Architecture and Technology (JC1403).

\section{References}

1. CHU Xi-jie, LI Wen, BAI Zong-qing, LI Bao-qing. Pyrolysis characteristics of Shenhua direct liquefaction residue [J]. Journal of Fuel Chemistry and Technology, 2009, 37(4):393-397.

2. Ouchi. Mechanism of hydrogenation of coal-derived asphaltene [J]. Fuel. 1978, 57:676-680.

3. ZHONG Jin-long, LI Wen-bo, SHI Shi-dong, ZHU Xiao-su. Solvent extraction research on organic matter in direct coal liquefaction residue [J]. Journal of China Coal Society. 2012, 37(2):316-322.

4. LIU Peng-fei, ZHANG Yong-qi, FANG Yi-tian. TG analysis of coal direct liquefaction residue and its solvent extract [J]. Journal of Fuel Chemistry and Technology. 2012, 40(4):656-659.

5. Motoyuki Sugano, Taku Tamaru, Katsumi Hirano, Kiyoshi Mashimo. Additive effect of tyre constituents on the hydrogenolyses of coal liquefaction residue [J]. Fuel. 2005, 84:2248-2255.

6. LI Jun, YANG Jian-li, LIU Zhen-yu. Hydrogenation of heavy liquids from a direct coal liquefaction residue for improved oil yield [J]. Fuel Processing Technology. 2009, 90:490-495.

7. LI Jun, YANG Jian-li, ZHOU Shu-fen, LI Yun-mei. Pyrolysis property of solvent extracts from a direct coal liquefaction residue [J]. Journal of Fuel Chemistry and Technology. 2010, 38(6):647-651.

8. SONG Yong-hui, LI Yan-xia, SHI Jun-wei, LAN Xin-zhe. Effect of Proportion of Coal Liquefaction Residue on Compressive Strength of Formed COKE [J]. Coal 
Conversion. 2014, 37(3):58-61.

9. GB/T2292-1977. Coking products-Determination of toluene insoluble content [S]. Beijing: Standards Press of China: 1997.

10. LIU Bao-lin. Pyrolysis characteristics of direct liquefaction residue [D]. Northwest University: 2012.

11. LI Jian-guang, FANG Yi-tian, ZHANG Yong-qi, LI Chun-yu, WANG Yang. Property of char from fast pyrolysis of direct coal liquefaction residue [J]. Journal of Fuel Chemistry and Technology. 2008, 36 (3):273-278.

12. LI Yang-yang. Study on Utilization of Coal Liquefaction Residues and Extraction of Aromatic Hydrocarbons from Coal Liquefaction Light Oil [D]. Journal of East China University of Science and Technology: 2010. 